\title{
PHOTOREGULATION OF $\alpha$-CHYMOTRYPSIN ACTIVITY IN ORGANIC MEDIA: EFFECTS OF BIOIMPRINTING
}

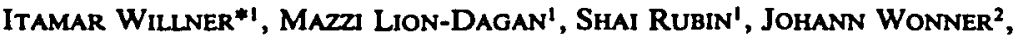 \\ Franz EFFenberger ${ }^{2}$ and PETER BÄUerLE ${ }^{2}$ \\ 'Institute of Chemistry and the Farkas Center for Light-Induced Processes, \\ The Hebrew University of Jerusalem, Jerusalem, 91904, Israel and \\ ${ }^{2}$ Institut für Organische Chemie und Isotopenforschung der Universität Stuttgart, \\ Pfaffenwaldring 55, 7000 Stuttgart 80, Germany
}

(Received 17 May 1993; accepted 2 December 1993)

\begin{abstract}
Chymotrypsin exhibits photoswitchable activities in an organic solvent after covalent modification of the protein backbone with thiophenefulgide active ester (2). The thiophenefulgide-modified $\alpha$-chymotrypsin exhibits reversible photoisomerizable properties between states (3)-E and (3)-C. The modified $\alpha$-chymotrypsin, where nine lysine residues are substituted by thiophenefulgide units, retains $60 \%$ of the activity of the native enzyme. The activities of thiophenefulgide-modified $\alpha$-chymotrypsin toward esterification of $N$-acetyl-L-phenylalanine (4) by ethanol in cyclohexane are controlled by the configuration of the attached photoisomerizable component and by prior bioimprinting of the protein backbone with the reaction substrate (4). The esterification of (4) in cyclohexane using bioimprinted (3)-C is two-fold faster than in the presence of (3)-E. In the presence of a nonbioimprinted enzyme, esterification of (4) by (3)-C is five-fold faster than with (3)-E. The activity of bioimprinted (3)-E toward esterification of (4) is 4.5-fold higher than that of nonbioimprinted (3)-E. Switchable cyclic esterification of (4) is accomplished by sequential photoisomerization of the thiophenefulgide-modified $\alpha$-chymotrypsin between states (3)-C and (3)-E.
\end{abstract}

\section{INTRODUCTION}

Photoregulation of protein activities and photoswitching of biological functionalities is of extensive interest from basic aspects to practical applications. ${ }^{1.2}$ Conversion of biomaterials into photoswitchable active substances provides the basis for bioelectronic materials and their use as image recording substances, ${ }^{3}$ light-activated reversible biosensor devices, ${ }^{\prime}$ light signal amplification systems $s^{4.5}$ and biological computer units ${ }^{6.7}$ can be envisaged. Further applications, such as light-stimulated targeted therapeutics and light-activated transport of chemicals, have been similarly discussed. ${ }^{1.8 .9}$ Several approaches to switch the functionalities of biomaterials "onoff" such as the biocatalytic activities of enzymes $10-12$ and binding properties of proteins were examined. ${ }^{10}$ These include chemical modification of the proteins by photoisomerizable components, ${ }^{10.11}$ application of photoregulated inhibitors ${ }^{12,13}$ and immobilization of biomaterials and photostimulated environments such as photosensitive polymers."

Photostimulation of proteins by covalent attachment of reversibly photoisomerizable components, i.e. papain or concanavalin $A, 10.13 .16$ is based on the concept that in the photoisomerizable state of the chemical units, the protein attains its tertiary bioactive structure and is in the "on" position, while photoisomerization to the complementary state results in distortion of the protein. This structural change perturbs the protein structure and its active site and as a result deactivates it toward its biological function, position "ofl" (Fig. 1). Although the concept proved to be successful, and structural changes in the protein backbones as a result of the photoisomerization process were revealed by transient lightscattering experiments, " only moderate switching efficiencies

To whom correspondence should be addressed. are observed. In fact, for various proteins such as $\alpha$-chymotrypsin, covalent attachment of photoisomerizable components does not lead to photostimulated activities, implying that the conformational perturbation of the protein backbone induced by the photoisomerization process is small.

The limited structural perturbation of the proteins, as a result of the photoisomerization reaction, could be partially attributed to their stabilization by intraprotein hydrogen bonds involving water molecules. Hence, the use of nonaqueous media for photostimulation of protein activities could be advantageous. Extensive research efforts are directed toward the use of organic solvents as reaction media for enzymatic reactions. ${ }^{18-20}$ Here, the enzyme tertiary structure is preserved by minute amounts of water that stabilize the protein configuration. Also, the preassembling of the enzymes by "bioimprinting" of the substrate structure into the protein backbone has been shown to be an effective means of activating enzymes in organic solvents and inducing selectivity in biocatalytic activities in organic solvents. ${ }^{2 \prime}$

Here we wish to report on the photostimulation of $\alpha$-chymotrypsin activities in an organic solvent by means of its chemical modification with photoisomerizable components. We reveal the effects of bioimprinting on enzyme activities and its photoswitchable functions. We show that while chemically modified $\alpha$-chymotrypsin does not exhibit photoswitchable activities in aqueous solutions, its biocatalytic functions can be triggered by light in the organic solvent.

\section{MATERIAIS AND METHODS}

2-(E)-[1-(2,5-dimethyl)-3-thienyl)ethylidene]-3-isopropylidenesuccinic anhydride (1) was prepared according to the literature. ${ }^{22} \mathrm{All}$ other chemicals and $\alpha$-chymotrypsin were of commercial source (Sigma). Spectroscopic measurements were performed on a Uvikon860 (Kontron) spectrophotometer. High-performance liquid chromatographic (HPLC) analyses were performed on a Merck Hitachi liquid chromatograph equipped with a UV detector. 


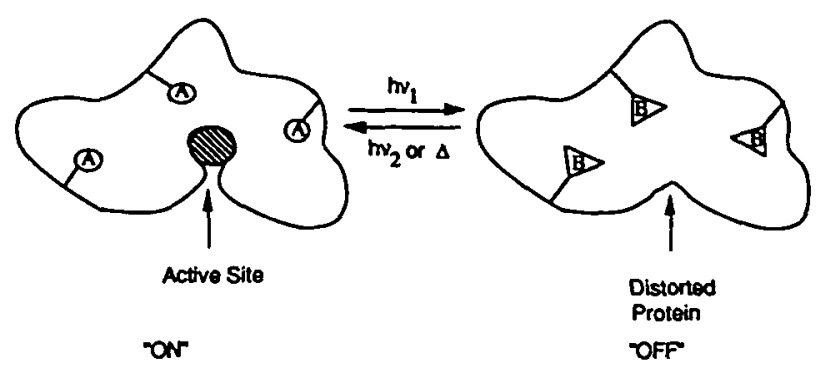

Figure 1. Schematic representation of the photostimulated "on-off" activities of an enzyme by chemical modification of a protein with photoisomerizable groups.

Chemical modification of $\alpha$-chymotrypsin (Sigma) by thiophenefulgide was carried out according to the following procedure: 100 $\mathrm{mg}$ of $\alpha$-chymotrypsin was dissolved in $12 \mathrm{~mL}$ of an aqueous solution that contained $500 \mathrm{mg} \mathrm{NaHCO}$. A solution of $40 \mathrm{mg}$ of $N-\{2-[1$ (2,5-dimethyl-3-thienyl)-ethylidene]-3-isopropylidenesuccinyl)glycine( $N$-hydroxysuccinimide) ester (2), in tetrahydrofuran (400 $\mu \mathrm{L})$ was added to the aqueous enzyme solution and the resulting mixture was allowed to react at $0^{\circ} \mathrm{C}$ for $24 \mathrm{~h}$. The mixture was dialyzed and the resulting solution was lyophilized to dryness. The loading of the resulting thiophenefulgide-modified $\alpha$-chymotrypsin by photoisomerizable units corresponds to 9 . The loading of the protein by thiophenefulgide units was determined by photochemical isomerization of a $2 \mathrm{~mL}$ solution that contains $2 \mathrm{mg}$ of the protein (3)-E to (3)-C and measurement of the resulting absorbance at $\lambda=$ $532 \mathrm{~nm}\left(\epsilon=2200 \mathrm{M}^{-1} \mathrm{~cm}^{-1}\right)$. Separation of $\alpha$-chymotrypsin by HPLC was performed by using a mixed mode vs reversed-phase column $\left(C_{12} /\right.$ cation, $7 \mu$ particles and pore size $300 \AA, 250 \mathrm{~nm}$ length and $4.6 \mathrm{~mm}$ diameter; Alltech). The eluent was a gradient mixture of acetonitrile and trifluoroacetic acid, $0.05 \%$ (solvent $A$ ) and water that includes trifluoroacetic acid, $0.1 \%$ (solvent B). At time zero the ratio of solvent $A: B$ is $10: 90$ and reached a value of $100 \%$ solvent $A$ at $\mathbf{2 0}$ min elution. Afterward the solvent mixture was gradually altered to reach after $35 \mathrm{~min}$ a ratio of solvent $A: B$ that corresponds to $10: 90$, respectively. Detection of the eluted proteins was followed at $\lambda=220 \mathrm{~nm}$.

Bioimprinting of (3)-E was performed with the substrate $N$-acetylL-phenylalanine (4). Thirty milligrams of (3)-E were dissolved in 1 $\mathrm{mL}$ of sodium phosphate buffer $\left(1 \times 10^{-2} \mathrm{M}, \mathrm{pH} 7.8\right)$ that contains (4) $\left(2 \times 10^{-2} M\right)$. The enzyme solution was cooled to $0^{\circ} \mathrm{C}$ and equilibrated for $2 \mathrm{~h}$. $n$-Propanol precooled to $-20^{\circ} \mathrm{C}(4 \mathrm{~mL})$ was then added to the solution. The resulting precipitate was washed three times with $n$-propanol followed by centrifugation and removal of the solvent and dried under vacuum.

Assaying the activities of a-chymotrypsin and of (3)-E and (3)-C in cyclohexane was performed by the following procedure: $8 \mathrm{mg}$ of the respective enzyme in imprinted or nonimprinted forms were suspended in $2 \mathrm{~mL}$ of cyclohexane that contained $0.5 \mathrm{~mL}$ of an ethanol solution of $N$-acetyl-L-phenylalanine, $0.1 M$ (final concentration of the substrate $2 \times 10^{-2} \mathrm{M}$ ). Eighty microliter samples were taken from the reaction mixture at time intervals and introduced into vials that contained a $9 \mathrm{~mm}$ RC $580.2 \mu$ filter (Schleicher \& Schuell). The vials were centrifuged to filter off the enzyme, and the reaction samples were analyzed by HPLC (RP-18 column, eluent solution methanol-water $65 \%-35 \%, 0.8 \mathrm{~mL} \mathrm{~min}^{-1}$, UV detection, $\lambda=254 \mathrm{~nm}$ ).

Photochemical experiments were performed by illumination of the enzyme substrate reaction mixture in a thermostated bath $\left(20^{\circ} \mathrm{C}\right)$ using appropriate light sources. For generation of the (3)-E protein state a $150 \mathrm{~W}$ xenon lamp equipped with a filter $(\lambda>475 \mathrm{~nm}$ ) was used. For generation of (3)-C a Hg pencil lamp source (Oriel, 6042 long wave filter) $320 \mathrm{~nm}<\lambda<400 \mathrm{~nm}$ was used. Illumination at the various wavelengths has been continuously applied during the experiments to eliminate thermal isomerization of (3)-C to (3)-E or uncontrolled roomlight isomerization of (3)-E to (3)-C.

Hydrolysis of $N$-acetyl-L-phenylalanine-ethylester (5) was assayed by the two isomer states (3)-E and (3)-C, respectively. The modified $\alpha$-chymotrypsin, (3)-E or (3)-C (4 mg) were introduced into $2.5 \mathrm{~mL}$ of an acetonitrile-water (3.2\% vol/vol) and the two photoisomer states were generated by illumination with the respective light sources for $30 \mathrm{~min}$. The substrate (5) was then injected to the enzyme solution $\left(2 \times 10^{-2} M\right)$ and the rate of formation of the product (4) was followed by HPLC.

Hydrolysis of $N$-succinyl-L-phenylalanine-p-nitroanilide (6) was followed also in the two enzyme states (3)-E and (3)-C. The modified enzyme $(0.2 \mathrm{mg})$ was dissolved in $2 \mathrm{~mL}$ of a triethanolamine buffer solution ( $0.2 \mathrm{M} . \mathrm{pH} 7.8)$. The resulting enzyme solution was illuminated for $30 \mathrm{~min}$ with the respective light sources, to generate the two photoisomer states (3)-E and (3)-C. The resulting enzyme solution was transferred into cuveltes and the substrate (6) was added $\left(4 \times 10^{-3} \mathrm{M}\right)$. The hydrolysis rate to product $(8)$ was followed spectroscopically $(\lambda=405 \mathrm{~nm})$.

\section{RESULTS AND DISCUSSION}

The reversible photoisomerization of fulgides and specifically thiophenefulgide (1) has been extensively studied. ${ }^{23}$ Thiophenefulgide (1)-E undergoes electrocyclization to (1)-C upon illumination in the wavelength region $320 \mathrm{~nm}<\lambda<$ $400 \mathrm{~nm}$. The cyclic isomer (1)-C photoisomerizes to (1)-E upon illumination ( $\lambda>475 \mathrm{~nm}$, Eq. 1). $\alpha$-Chymotrypsin was chemically<smiles>CC(C)=C1C(=O)O[C@H](C#CC2=CC3=C(C)C4=C(C(=O)OC4=O)C(C)(C)C3(C)S2)C1=O</smiles>

(1)-E

(1)-C

modified by thiophenefulgide residues by reacting its lysine residues with the active ester derivative, $N-\{2-[1-(2,5$-dimethyl3-thienyl)-ethylidene]-3-isopropylidenesuccinyl \}glycine ( $N$-hydroxy-succinimide) ester (2), according to Eq. 2. The resulting thiophenefulgide-modified $\alpha$-chymotrypsin, (3)-E exhibits reversible photoisomerization properties (Eq. 3). The photoisomerization is followed spectroscopically as outlined in Fig. 2 . The loading of $\alpha$-chymotrypsin by thiophenefulgide units was determined by following the absorbance of (3)-C at $\lambda=532 \mathrm{~nm}\left(\epsilon=2200 \mathrm{M}^{-1} \mathrm{~cm}^{-1}\right)$ and concomitant determination of the protein content. The derived average loading corresponds to 9 . That is, out of 13 lysine residues comprising the enzyme backbone, 9 are derivatized by thiophenefulgide. Figure 3 shows the HPLC chromatograms of native $\alpha$-chymotrypsin (Fig. 3a) and of thiophenefulgidemodified $\alpha$-chymotrypsin (3)-E (Fig. 3b). We see that the modified protein does not contain the native $\alpha$-chymotrypsin. In addition we realize that the chromatogram of (3)-E includes a sharp main product eluted at $10.60 \mathrm{~min}$, under the experimental conditions, and some minor products that appear as impurities. This suggests that modification of $\alpha$-chymotrypsin by thiophenefulgide yields a rather pure protein (and not a mixture) even though only 9 lysine residues (out of 13) are derivatized. Thus, presumably 9 lysine residues are exposed toward the chemical modification that result in the pure modified protein. Experiments are now being done to sequence this protein and identify the thiophenefulgide linkage sites. Furthermore, the activity of the thiophenefulgide-modified $\alpha$-chymotrypsin in cyclohexane solution has been compared to that of native $\alpha$-chymotrypsin. Figure 4 shows the esterification rates of (4) by ethanol in a cyclohexane solution using bioimprinted native $\alpha$-chymo- 


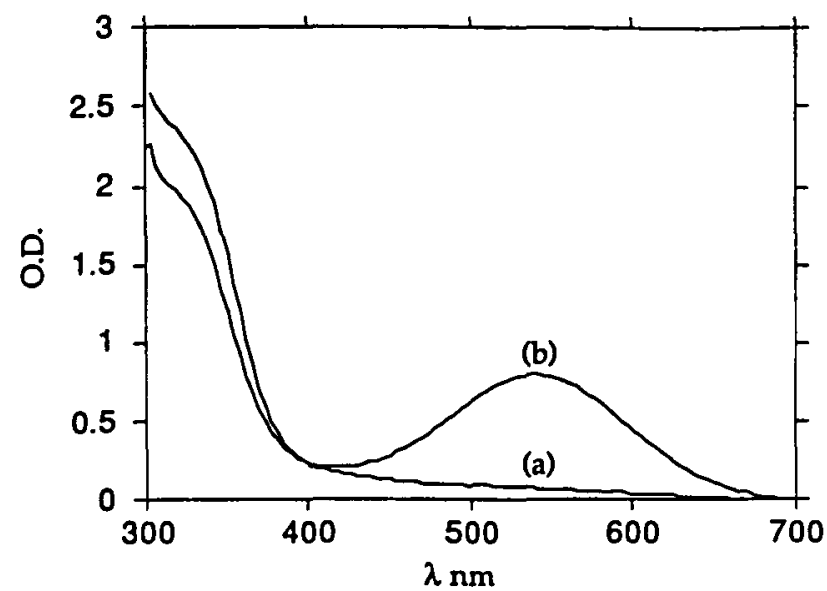

Figure 2. Absorption spectra of thiophenefulgide-modified $a$-chymotrypsin (1 mg protein/mL). (a): Spectrum of (3)-E. (b): Spectrum of (3)-C.

trypsin and bioimprinted (3)-C protein state (active form of thiophenefulgide-modified $\alpha$-chymotrypsin). It is evident that protein (3).C retains $60 \%$ of the activity of the native enzyme.<smiles></smiles>

(2)<smiles>CC(C)=C1C(=O)N(CC(=O)NC2CC3CCC2C3)C(=O)C1=C(C)c1cc(C)sc1C</smiles>

The activities of thiophenefulgide-modified $\alpha$-chymotrypsin in cyclohexane were determined by following the esterification of $N$-acetyl-L-phenylalanine (4) by ethanol to form (5) (Eq. 4). Figure 5 shows the rate of formation of (5) by thiophenefulgide-modified $\alpha$-chymotrypsin in the (3)-E state that is bioimprinted by the substrate (4)<smiles>C=CC=C1CC2CCCCC12</smiles><smiles>[124In]</smiles><smiles>CC1=CC2=C(C)C3=C(C(=O)N(CC(=O)NC4CCCC4)C3=O)C(C)(C)C2(C)S1</smiles>

(3)-C
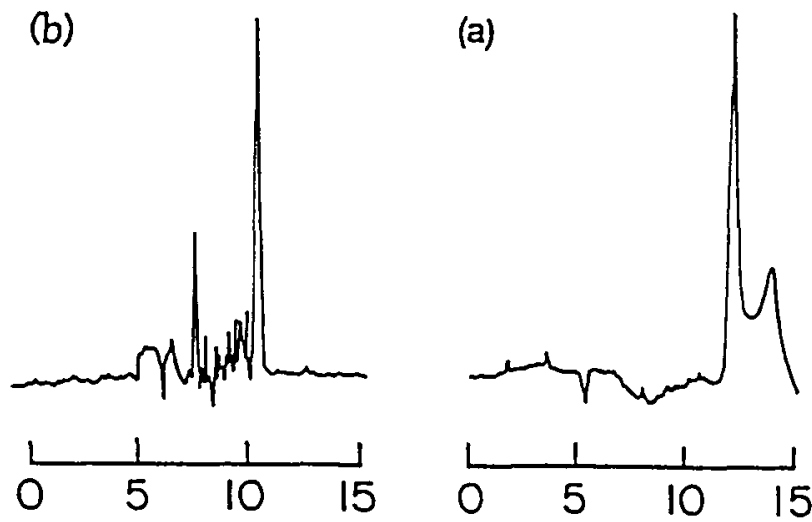

Figure 3. High-performance liquid chromatograms for (a) native $\alpha$-chymotrypsin and (b) thiophenefulgide-modified $\alpha$-chymotrypsin. For separation conditions see Materials and Methods.<smiles>CC(=O)NC(Cc1ccccc1)C(=O)O</smiles>

(4)<smiles>CCOC(=O)C(Cc1ccccc1)NC(C)=O</smiles>

(5)

(Fig. Sa), prior to its application in the esterification process, in comparison to the rate of the reaction in the presence of

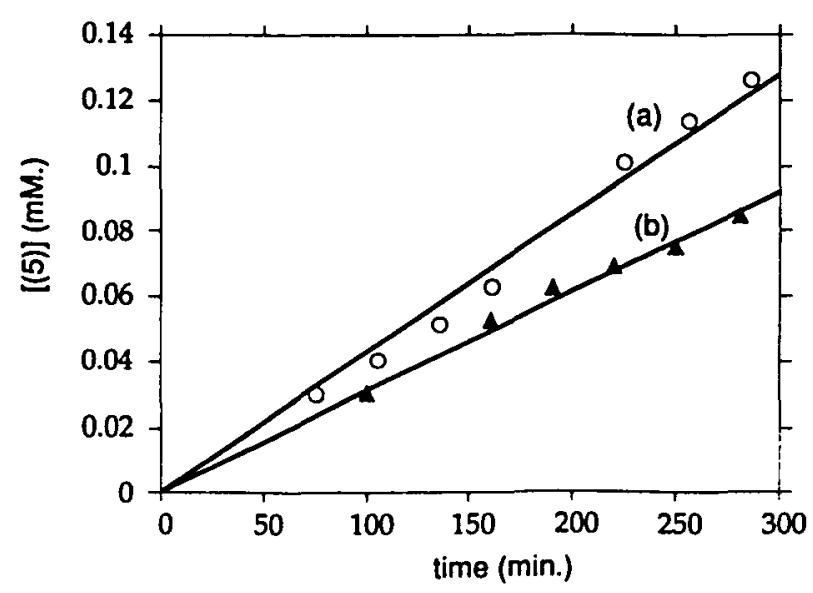

Figure 4. Rates of esterification of (4) by ethanol $(0.5 \mathrm{~mL})$ in cyclohexane ( $2 \mathrm{~mL}$ ) using (a) bioimprinted native $\alpha$-chymotrypsin (350 units) and (b) bioimprinted (3)-C protein (350 units). 


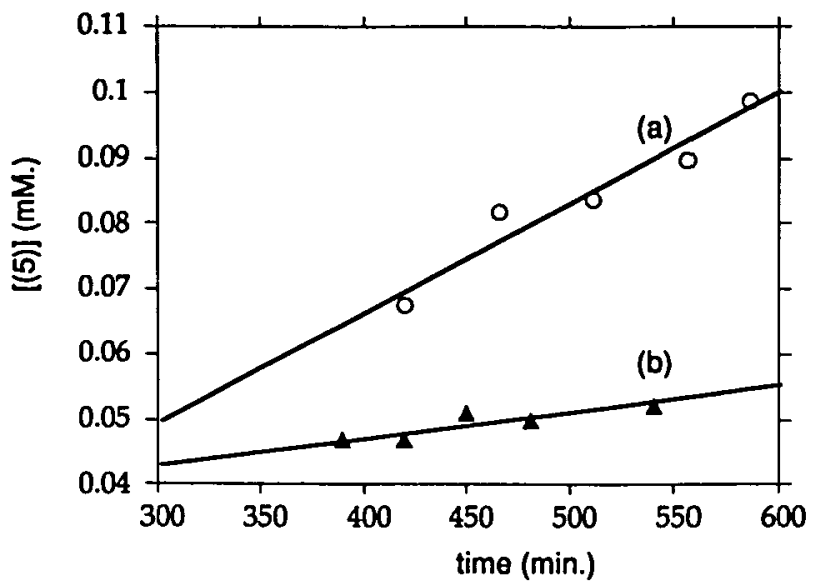

Figure 5. Rates for the esterification of $N$-acetyl-L-phenylalanine (4) $2 \times 10^{-2} \mathrm{M}$, by ethanol in cyclohexane using (3)-E (8 mg enzyme in $2 \mathrm{~mL}$ cyclohexane that include $0.5 \mathrm{~mL}$ of ethanol). (a): Enzyme is bioimprinted by (4) prior to the reaction. (b): Nonimprinted enzyme is applied.

a nonbioimprinted-modified enzyme, (3)-E (Fig. 5b). Evidently, the rate of (5) formation with the substrate bioimprinted biocatalyst is ca 4.5-fold higher than with the nonimprinted enzyme. The improved activity of the substrate bioimprinted enzyme is attributed to the restoration of the enzyme active site configuration by the imprinting procedure. That is, the active site retains its spatial catalytic configuration by association of the substrate within the process of precipitation from the aqueous phase. Introduction of the enzymes in imprinted or nonimprinted forms in the organic solvent involves perturbations of the protein backbone. Yet, due to the tight association of the substrate to the active site in the bioimprinted $\alpha$-chymotrypsin, such structural perturbations on the active site are minimal as compared to those experienced by a nonimprinted biocatalyst. As a result, the bioimprinted enzyme exhibits superior activity in the organic solvent.

The photoswitchable activity of thiophenefulgide-modified $\alpha$-chymotrypsin (3) is shown in Fig. 6. The esterification process is performed with the substrate bioimprinted biocatalyst, (3)-E state. A slow esterification rate, corresponding to $1.6 \times 10^{-7} \mathrm{M} \mathrm{min}^{-1}$ is observed (Fig. 6A). At the time marked with an arrow, the enzyme suspension is illuminated (320 $\mathrm{nm}<\lambda<400 \mathrm{~nm}$ ) and transferred to the (3)-C state. An enhancement in the rate of (5) formation is observed, that corresponds to $\mathrm{v}=3.2 \times 10^{-7} \mathrm{M} \mathrm{min}^{-1}$ for the ester formation. The photoactivation/deactivation cycle can also be reversed as shown in Fig. 6B. Here the esterification process is initiated by the biocatalyst in the (3)-C state and rapid formation of (5) is observed. At the time marked with the arrow, the system which includes (3)-C is illuminated with visible light $(\lambda>475 \mathrm{~nm})$ and the enzyme is converted into the (3)-E form. The esterification reaction is retarded in the presence of the biocatalyst in the (3)-E state. These results clearly indicate that the activity of thiophenefulgide-modified $\alpha$-chymotrypsin is photostimulated in the organic solvent medium. The (3)-C state of the biocatalyst is twice more active than the (3)-E state.
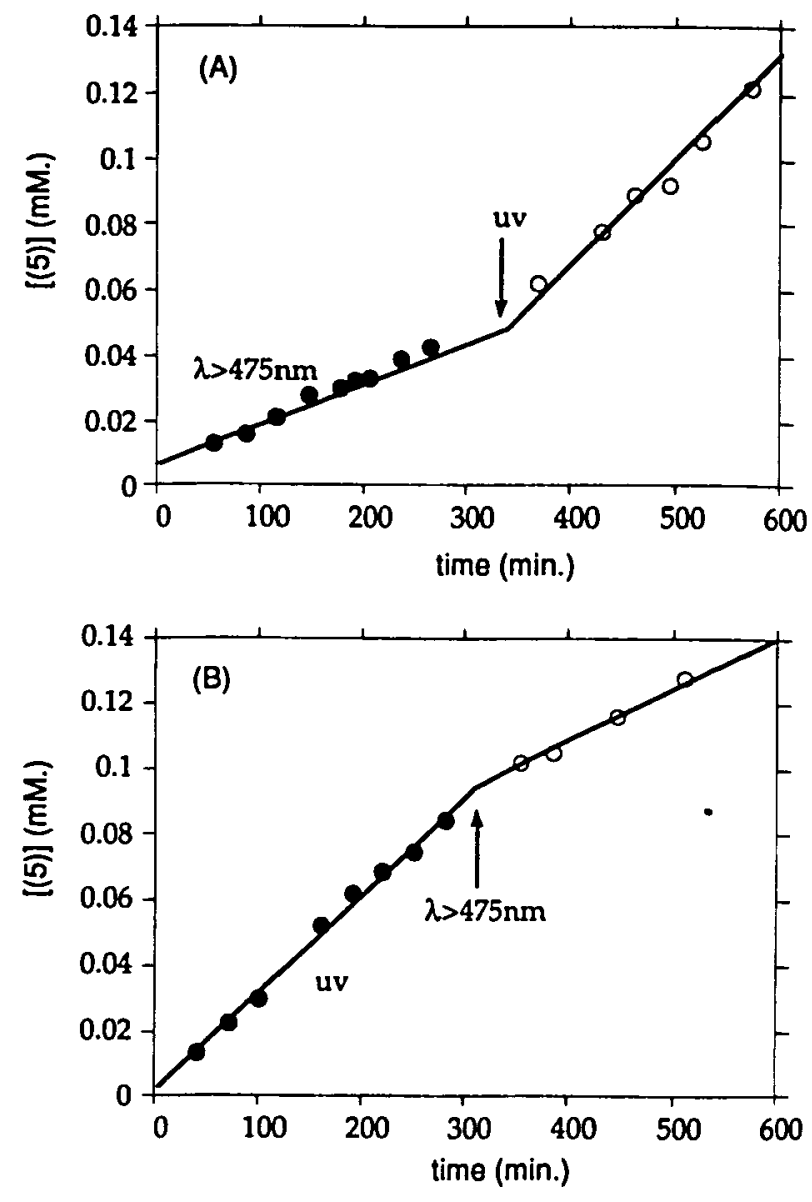

Figure 6. Photostimulated rates of esterification of $(4)\left(2 \times 10^{-2}\right.$ $M)$ by ethanol in cyclohexane using bioimprinted thiophenefulgidemodified $\alpha$-chymotrypsin $(8 \mathrm{mg}$ in $2 \mathrm{~mL}$ cyclohexane that includes $0.5 \mathrm{~mL}$ ethanol). (A): Esterification is initiated by protein in the (3)-E state. Arrow indicates transformation of the (3)-E to (3)-C state. (B): Esterification is initiated with (3)-C state. At time indicated by arrow protein is converted to (3)-E state.

The system was further examined as an assembly for photoinduced cyclic switching of $\alpha$-chymotrypsin activities (Fig. 7). Here we see that the cycle is initiated by the (3)-E biocatalyst state and slow esterification of (4) is observed. At the time indicated by the arrow (a), the system is illuminated ( $320 \mathrm{~nm}<\lambda<400 \mathrm{~nm}$ ) and the biocatalyst is transformed to the (3)-C form. Accordingly, the biotransformation is enhanced and the reaction is switched "on." At the time indicated by the arrow (b), the system is illuminated with visible light $(\lambda>475 \mathrm{~nm})$ and the reaction is again retarded corresponding to a switched "off" state.

Photostimulation of $\alpha$-chymotrypsin modified by thiophenefulgide (3) was examined also in cyclohexane as reaction medium without prior bioimprinting of the enzyme (Fig. 8). As stated earlier, the enzyme (3) that lacks substrate imprint is ca 4.5-fold less active than the bioimprinted biocatalyst. Accordingly, application of the nonimprinted enzyme in the (3)-E state as biocatalyst results in very slow esterification of (4). Upon transformation of the biocatalyst to the (3)-C state by illumination ( $320 \mathrm{~nm}<\lambda<400 \mathrm{~nm}$ ), a sharp enhancement in the reaction rate is observed. Evidently, with 


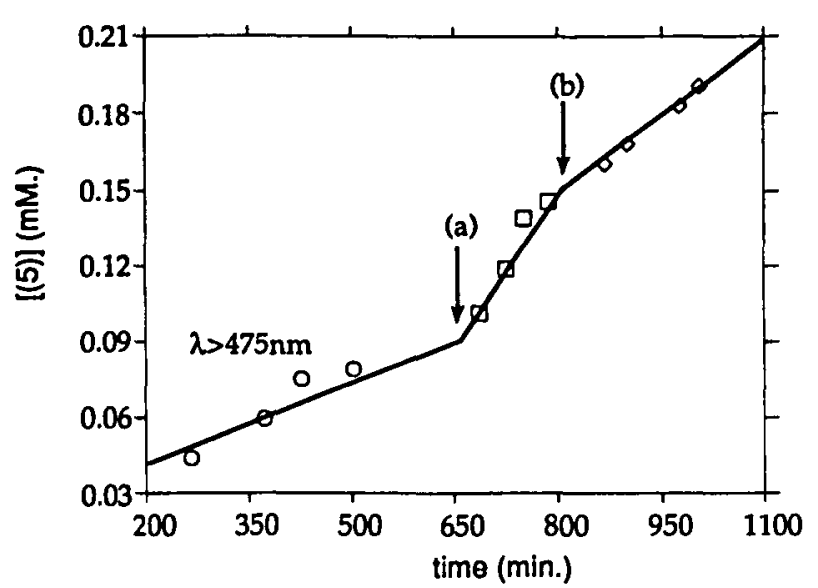

Figure 7. Cyclic photoswitchable activities of thiophenefulgidemodified $\alpha$-chymotrypsin. Experimental conditions are as detailed in Fig. 6. Experiment is initiated with (3)-E state. At time indicated by arrow (a) protein is converted to (3)-C state; at time indicated by arrow (b) the protein is retransformed to state (3)-E.

the nonimprinted biocatalyst the (3)-C form is five-fold more active than the (3)-E state of the biocatalyst. Thus, improved switching efficiencies are detected for the nonimprinted biocatalyst as compared to imprinted enzyme, where the activity of the (3)-C form is only two-fold higher than that of (3)-E. Nonetheless, the absolute conversion yields of (4) to (5) are higher with bioimprinted thiophenefulgide-modified $\alpha$-chymotrypsin. These results are rationalized in terms of structural changes induced in the protein backbone by the photoactive isomerizable units that lead to the photostimulated "on-off" bioactivities and to structural rigidity of the active site structure induced by the substrate imprinting process: Photoisomerization of the thiophenefulgide residues involves a substantial structural change. Molecular mechanics calculations for the two thiophenefulgide isomers indicate that the isomer (1)-C is sterically compact as compared to (1)-E, which reveals a high steric volume. Accordingly, $\alpha$-chymotrypsin in the (3)-C configuration attains the active site configuration for high biocatalytic activity (switch "on"). Upon photoisomerization of (3)-C to (3)-E the protein is sterically distorted and the active site structure is perturbed (switch "off'). The bioimprinting process by the substrate results, however, in rigidity of the active site configuration. As a result, isomerization of (3)-C to (3)-E leads to a lesspronounced steric perturbation of the active site. This leads to a lower switching efficiency of the biocatalyst as compared to the nonimprinted enzyme. The imprinting procedure, however, leads to a higher activity of the biocatalyst in the organic solvent due to rigid conformation of the active site in this medium.

A further aspect that is to be considered relates to the possible photoactivation of (3) in aqueous media. For this purpose, we examined the hydrolysis of $N$-acetyl-L-phenylalanine-ethyl ester (5) by the two biocatalyst states (3)-E and (3)-C(Fig. 9). It is evident that the hydrolysis of (5) to produce (4) in the aqueous medium is identical by the two states. Similarly, hydrolysis of $N$-succinyl-L-phenylalanine-p-nitroanilidine (6) to form (7) and (8) (Eq. 5) reveals identical rates by the two biocatalyst forms (3)-C and (3)-E. These

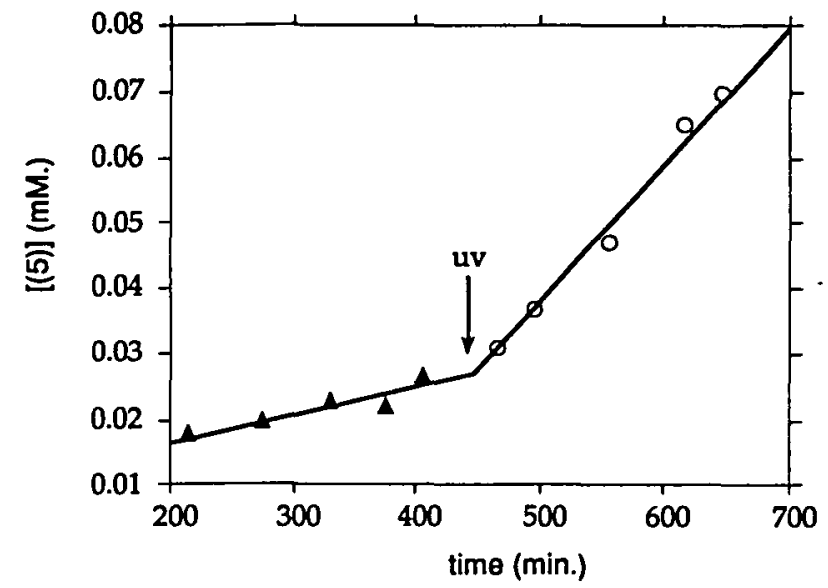

Figure 8. Photostimulated activity of thiophenefulgide-modified $\alpha$-chymotrypsin without imprinting. Experiment is initiated by (3)-E state. At time indicated by arrow the protein is transformed to (3)-C state.

results imply that isomerization of (3)-C to (3)-E in aqueous media does not effect significant structural perturbations of the protein backbone to induce photostimulated activities.

We thus conclude that the aqueous reaction medium stabilizes the tertiary structure of the protein against steric perturbations originating from isomerization of the photoactive units. In turn, in organic solvents only minute amounts of water participate in stabilization of the proteins. Photoisomerization of the thiophenefulgide residues in this latter reaction medium and the resulting steric strain are sufficient to disrupt the stabilizing effect of associated water and to effect distortion of the protein.<smiles>O=C(O)CCC(=O)NC(Cc1ccccc1)C(=O)Nc1ccc([N+](=O)[O-])cc1</smiles>

(6)<smiles>O=C(O)CCCCCCCC(=O)NC(Cc1ccccc1)C(=O)O[NH2+]c1ccc([N+](=O)[O-])cc1</smiles>

(8)

\section{CONCLUSIONS}

We have demonstrated the advantages of using organic solvents as reaction medium to photostimulate the activities of enzymes that are modified by photoisomerizable components. It is demonstrated that the photoisomerizable units can effect an increased structural perturbation in the protein configuration in the organic phase, as compared to an aqueous medium. Furthermore, the switching efficiency and the biocatalyst activities in the organic phase are controlled by 


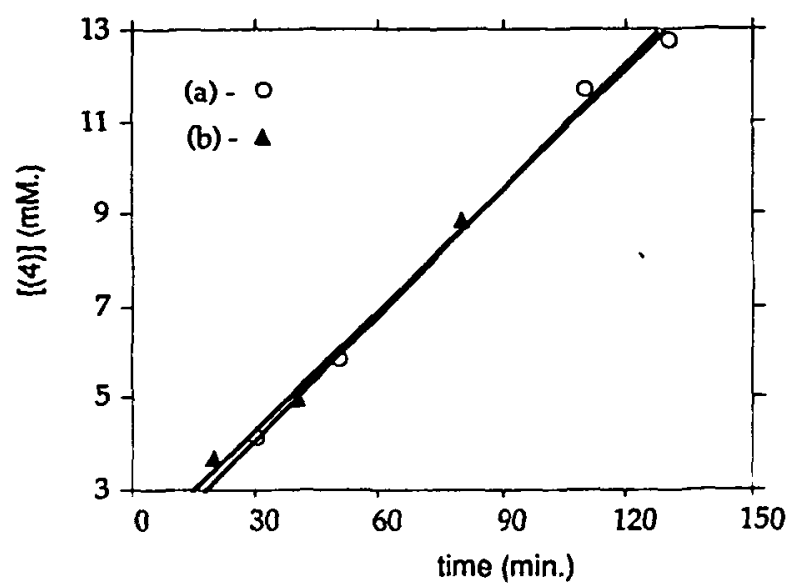

Figure 9. Hydrolysis of $N$-acetyl-L-phenylalanine ethyl ester (5) (2 $\times 10^{-2} M$ ) by thiophenefulgide-modified $\alpha$-chymotrypsin $(4 \mathrm{mg}$ ) (a) by (3)-E state and (b) by (3)-C state.

the substrate-bioimprinting process. The bioimprinted protein reveals enhanced biocatalytic activity in the organic solvent but the switching efficiency is moderate. This is due to limited steric perturbation of the active site configuration, which is held in a rigid structure by the bioimprinted substrate. In turn, the enzyme that lacks the substrate imprint shows high switching efficiency as a result of substantial structural distortion of the active site by the photoisomerizable units. Further studies to apply other photoisomerizable compounds such as spiropyran and application of photoisomerizable inhibitors as imprints to photoregulate enzyme activities in organic solvents are now being examined in our laboratory.

Acknowledgement-This research was supported by The Basic Research Foundation administered by The Israel Academy of Sciences and Humanities.

\section{REFERENCES}

1. Willner, I. and B. Willner (1993) Chemistry of photobiological switches. In Bioorganic Photochemistry-Biological Applications of Photochemical Switches. Vol. 2 (Edited by H. Morrison), pp. 1-110. Wiley, New York.

2. Lester, H. A. and J. M. Nerbonne (1982) Physiological and pharmacological manipulations with light flashes. Annu. Rev. Biophys. Bioeng. 11, 151-175.

3. Hariharan, P. (1984) Optical Holography. Academic Press, Cambridge.

4. Hug, D. (1978) The activation of enzymes with light. Photochem. Photobiol. Rev. 3, 1-33.

5. Martinek, K and I. V. Berezin (1979) Artificial light-sensitive enzymatic systems as chemical amplifiers of weak light signals. Pholochem. Photobiol. 29, 637-649.
6. Parthenopoulos, D. A. and P. M. Rentzepis (1989) Threedimensional optical storage memory. Science 245, 843-845.

7. Liu, Z. F., K. Hashimoto and A. Fujishima (1990) Photoelectrochemical information storage using an azobenzene derivative. Nature 347, 658-660.

8. Wiliner, I., S. Sussan and S. Rubin (1992) Photostimulated transport of carboxylate and phenolate anions across a liquidliquid membrane using a photochromic cationic copolymer as carrier. J. Chem. Soc. Chem. Commun., pp. 100-101.

9. Balasubramanian, D., S. Subramani and C. Kumar (1975) Modification of a model membrane structure by embedded pho. tochrome. Nature 254, 252-254.

10. Willner, I., S. Rubin and A. Riklin (1991) Photoregulation of papain activity through anchoring photochromic azo groups to the enzyme backbone. J. Am. Chem. Soc. 113, 3321-3325.

11. Aizawa, M., K. Namba and S. Suzuki (1977) Photocontrol of enzyme activity of $\alpha$-amylase. Arch. Biochem. Biophys. 182, 4148.

12. Bieth, J., S. M. Vratsanos, N. H. Wassermann, A. G. Cooper and B. F. Erlanger (1973) Photoregulation of biological activity by photochromic reagents. Inactivators of acetocholinesterase. Biochemistry 12, 3023-3027.

13. Galley, K. T., M. DeSorgo and W. Prins (1973) The active site of acetylcholinesterase probed by a photochromic ligand. Biochem. Biophys. Res. Commun. 50, 300-307.

14. Willner, I., S. Rubin and T. Zor (1991) Photoregulation of $\alpha$-chymotrypsin by its immobilization in a photochromic azobenzene copolymer. J. Am. Chem. Soc. 113, 4013-4014.

15. Willner, I., S. Rubin, J. Wonner, F. Effenberger and P. Bäuerle (1992) Photoswitchable binding of substrates to proteins: photoregulated binding of $\alpha$-D-mannopyranose to concanavalin $A$ modified by a thiophenefulgide dye. J. Am. Chem. Soc. 114, 3150-3151.

16. Willner, I., S. Rubin and Y. Cohen (1993) Photoregulated binding of spiropyran modified concanavalin A to monosaccharide functionalized self-assembled monolayers of gold electrodes. J. Am. Chem. Soc. 115, 4937-4938.

17. Zahavy, E., S. Rubin and I. Willner (1993) Examination of conformational dynamics of photoregulated concanavalin $A$ by time-resolved light scattering. J. Chem. Soc. Chem. Commun. pp. $1753-1755$

18. Dordic, J. S. (1989) Enzymatic catalysis in monophasic organic solvents. Enzyme Microb. Technol. 11, 194-211.

19. Dordic, J.S. (1991) Principles and applications of nonaqueous enzymology. In Applied Biocatalysis, Vol. 1 (Edited by H. W. Blanch and D. S. Clark), pp. 1-51, Marcel Dekker, New York.

20. Chen, C. S. and C. J. Sih (1989) General aspects and optimization of enantioselective biocatalysis in organic solvents: the use of lipases. Angew. Chem. Int. Ed. Engl. 28, 695-707.

21. Stahl, M., V. J. Wistrand, M. O. Mansson and K. Mosbach (1991) Induced stereoselectuvity and substrate selectivity of bioimprinted $\alpha$-chymotrypsin in anhydrous organic media. $J$ Am. Chem. Soc. 113, 9366-9368.

22. Glaze, A. P., S. A. Hams, H. A. Heller, W. Johncock, S. N Oliver, P. J. Strydom and J. Whittal (1985) Photochromic heterocyclic fulgides. Part 4. The thermal and photochemical reactions of (E)-1sopropylidene-[ $\alpha-(2-$ and (3-thienyl)ethylidenelsuccinic anhydndes and related compounds J. Chem. So Perkin Trans. I. pp. 957-961.

23. Whittal, J. (1990) 4n + 2 Systems: fulgides. In Photochromism Molecules and System (Edited by H. Dürr and H. Bouas-Laurent), pp. 467-491. Elsevier, Amsterdam, The Netherlands. 